\title{
Aspects of growth in Arctic cod, Boreogadus saida (Lepechin 1773)
}

TOR JENSEN, KARL INNE UGLAND and MORTEN ANSTENSRUD

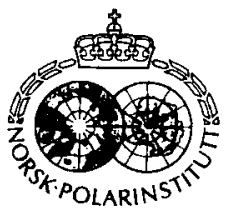

\begin{abstract}
Jensen, T., Ugland, K. I. \& Anstensrud, M. 1991: Aspect of growth in Arctic cod, Boreogadus saida (Lepechin 1773). Pp. 547-552 in Sakshaug, E., Hopkins, C. C. E. \& Oritsland, N. A. (eds.): Proceedings of the Pro Mare Symposium on Polar Marine Ecology, Trondheim, 12-16 May 1990. Polar Research 10(2).

In June 1986, 42 young Arctic cod were caught in ice-covered waters of the Barents sea with dip-nets by scuba divers. From August to June 1987 the fish were kept at $-1{ }^{\circ} \mathrm{C}$ and fed on frozen shrimp (Pandalus borealis). Length and weight were measured monthly. A fast weight increment of about $0.7 \%$ per day was observed in the autumn (Scpt.-Nov.). In the winter (Jan.-Feb.), the growth rate declined to $0.05 \%$ per day. However, daily food intake only decreased by $50 \%$ during these winter months. Since the fish were exposed to constant illumination in the aquarium, this growth experiment indicates that something else than light has a significant influence on growth in Arctic cod.

Tor Jensen*, Karl Inne Ugland and Morten Anstensrud. Institute of Biology. University of Oslo. P.O. Box 1074 Blindern, N-0316 Oslo 3. Norway (revised January 1991).

*Present address: Veritas Miljøplan A/S, P.O. Box 300, N-1322 Høvik. Norway.
\end{abstract}

\section{Introduction}

The Arctic cod (Boreogadus saida) is a small cod fish with a circumpolar distribution (Andriashev 1964). It is an important component of marine Arctic food webs (Klumov 1937), and it is one of the key species which transforms energy from lower to higher trophic levels. At ice edges the seabirds (fulmars, kittiwakes, murres, guillemots) and marine mammals (ringed seal, narwhal) depend on Arctic cod as a major component of their diets (Bradstreet 1982; Bradstreet et al. 1986).

The life span of Arctic cod rarely exceeds five years. They spawn during the winter and larvae hatch after about 80 days $\left(-1.5^{\circ} \mathrm{C}\right.$ ) (Altukhov 1979). Growth of the young of the year is relatively rapid. According to Rass (1968), newly emerged larvae are about $5.5 \mathrm{~mm}$ long, and transformation to the juvenile (fry) stages occurs when the young are $30-50 \mathrm{~mm}$ long. At age one the average length varies between 60 and $100 \mathrm{~mm}$ (Rass 1968; Hognestad 1968; Sekerak 1982; Craig et al. 1982). However, there are large temporal and regional differences in the growth of the species (Bradstreet et al. 1986). The average length of age group five ranges from 180 to $250 \mathrm{~mm}$.

The feeding ecology of juvenile/adult Arctic cod has been subject to several recent studies (Bain \& Sekerak 1978; Lowry \& Frost 1981; Bradstreet \& Cross 1982; Craig et al. 1982; Lønne \& Gulliksen 1989). Principal prey items are cope- pods, amphipods, mysids and fish. The young of the year prefer the early stages of calanoid copepods (Bradstreet et al. 1986).

The energy requirements for the growth of Arctic cod is unknown. The main aim of this study was to obtain more information on the energy demand for growth by feeding under controlled conditions in the laboratory.

\section{Material and methods}

135 Arctic cod were caught from 6 different localities in the western Barents Sea (between $75^{\circ} 77^{\prime} \mathrm{N}, 28^{\circ} 57^{\prime} \mathrm{E}$ and $77^{\circ} 27^{\prime} \mathrm{N}, 27^{\circ} 36^{\prime} \mathrm{E}$ ) during a trip carried out by the research vessel R/V LANCE (21 May-10 June 1986). Arctic cod were collected by scuba divers under the pack ice in first-year ice, between and underneath ice floes.

Throughout the cruise with R/V LANCE the Arctic cod were carefully kept in 5001 tanks with circulating seawater. Injured fish were removed since they would not survive the long trip from the Barents Sea to the laboratory in Oslo.

Forty-two of the 135 Arctic cod were placed in an aquarium system, which was set up in a coolingroom at University of Oslo. Two 6001 PVC tanks and one 1500 I square PVC-tank were connected to a 4001 gravel filter consisting of shell gravel and activated carbon pellets. The room was illuminated throughout the experiment by flu- 
orescent lighting with a light intensity (measured 1 metre above the floor) of 200 lux (AEG luxmeter). The aquarium water was cooled down to a suitable temperature $\left(-1^{\circ} \mathrm{C}\right)$ by circulating cold glycol solution (50\%) through a $9 \mathrm{~m}$ long glass coil $(\varnothing=20 \mathrm{~mm})$ placed in the $1500 \mathrm{l}$ tank.

Before the feeding experiment was begun, the fish were trained to accept peeled shrimp (Pandalus borealis) from human hands. As far as we could observe, the fish adjusted to the new laboratory environment, and there were no significant signs of stress which could bias our measurements. The fish were then fed to saturation four times a week on subsamples of the same initial pool of frozen shrimps from the Barents Sea. The food composition and the energy content of the food did not, therefore, change during the experiment. The fish had been sorted into size-groups which were kept separately to avoid cannibalism. Because the fish grew at different rates, it was necessary to transfer them from one aquarium to another several times during the experiment. Therefore, the number of Arctic cod in the aquarium varies throughout the experiment. There was no attempt to examine the sex ratio of the Arctic cod. No one fish was visibly mature at the beginning of the experiment.

The growth experiment was begun in August 1986 and completed in June 1987. Every month from August to December, and thereafter every
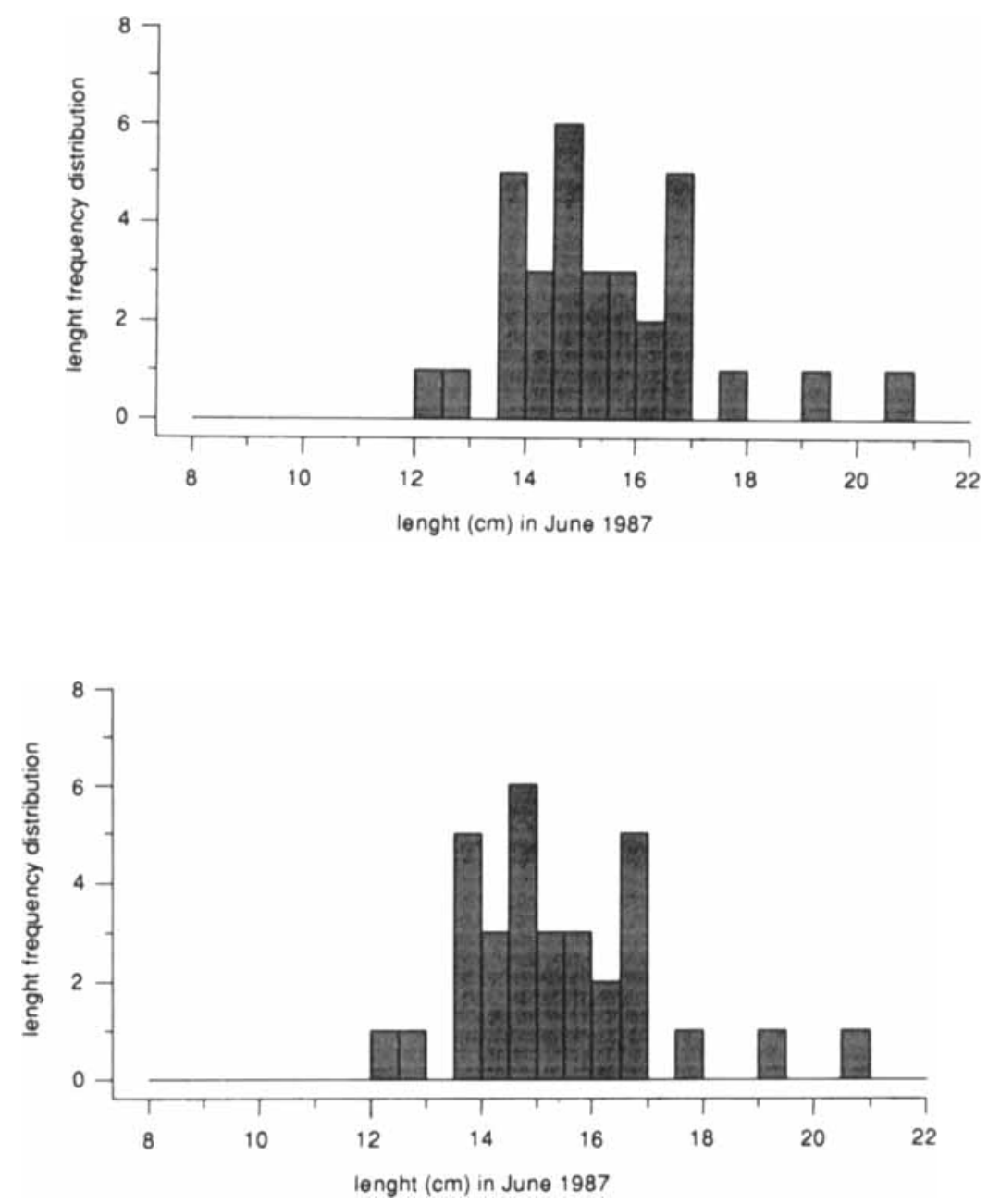

Fig. 1. Length frequency of Arctic cod (Boreogadus saida) at the beginning of the experiment (August 1986) and at the end (June 1987). 
second month, the length (fork length) and weight were measured to the nearest $1 \mathrm{~mm}$ and $0.1 \mathrm{~g}$ respectively. After each feeding any surplus of shrimp was collected and the weight measured.

Peeled shrimp has an energy content of $1.03 \mathrm{kcal} / \mathrm{g}$. Shrimp was chosen as the food source because it was the best approximation to the natural diet which could be guaranteed at a constant supply; using shrimp also allows the experiment to easily be repeated. In addition, the fish are provided with a diet which throughout the year has a constant proximate composition and energy per mass content.

The two most important factors that influenced appetite and food consumption were the water temperature and fish size. For a particular species appetite (daily energy intake) is normally greatest at a certain temperature and reduced at both higher and lower temperatures. In this experiment we did not examine the effect of the temperature since this was held constant at $-1^{\circ} \mathrm{C}$. When some of the fish had died between two consecutive measurements we assumed that the dead fish consumed shrimps during half the period between the measurements. The calculation of the average consumption per day per fish is then straightforward. The specific growth rate is defined as

$$
\mathrm{G}=\ln \left(\mathrm{w}_{2} / \mathrm{w}_{1}\right) /\left(\mathrm{t}_{2}-\mathrm{t}_{2}\right) \times 100 \text { (Jobling 1983) }
$$

where $w_{1}$ and $w_{2}$ denote the weight at time $t_{1}$ and $t_{2}$.

\section{Results}

Arctic cod caught from the Lance cruise in 1986 consisted of year classes I and II. In these two year classes the mean length was $82 \mathrm{~mm}$ (s.d. = 8.2 ) and $113 \mathrm{~mm}$ (s.d. $=4.1$ ) respectively. Initially there wree 42 individuals; at the end only 32 were alive.

At the start of the experiment (August 1986) nearly $65 \%$ of the fish were between 9 and $11 \mathrm{~cm}$, and at the end of the experiment (June 1987) 84\% of the fish were between 13.5 and $17 \mathrm{~cm}$ (Fig. 1).

As observed in Fig. 2, the average length increased from $107 \mathrm{~mm}$ (s.d. $=17.0$ ) to $156 \mathrm{~mm}$ (s.d. $=17.6$ ), and in the same period the average weight increased from $10 \mathrm{~g}$ (s.d. $=5$ ) to $34 \mathrm{~g}$ (s.d. = 18).

The specific growth rate of the weight (i.e. G) and the consumed energy per day per fish are

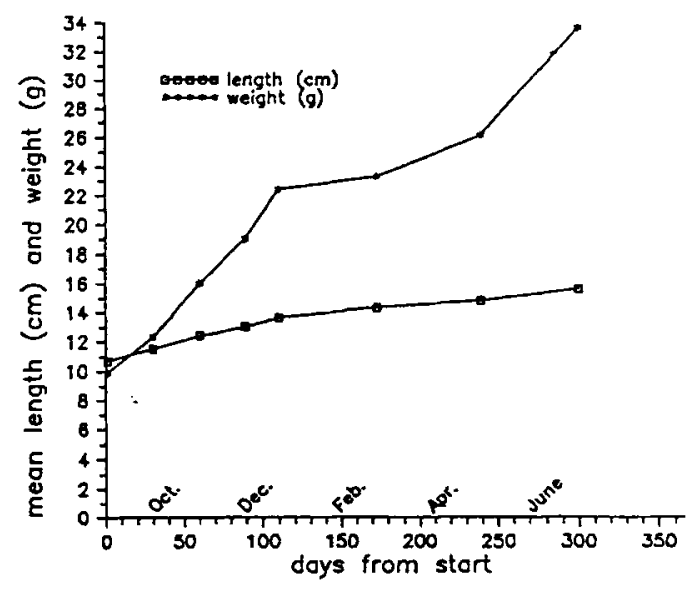

Fig. 2. Average monthly weight $(\mathrm{g})$ and length $(\mathrm{cm})$ of Arctic cod (Boreogadus saida).

shown in Figs. 3 and 4. It is observed that the average specific growth rate is about 0.7 per day in the autumn (Sept., Oct., Nov.). Thus the mean weight increment per day was $0.7 \%$ in the autumn. Then the specific growth rate decreased to 0.4 in December, and further declined to a mean value of 0.12 in the winter (Jan., Feb., March). This corresponds to an average weight increment of only $0.1 \%$ in these three months. In spring (April-June) the growth rate increased to the December level.

The consumption per day per fish did not vary as much as the specific growth rate. In the period

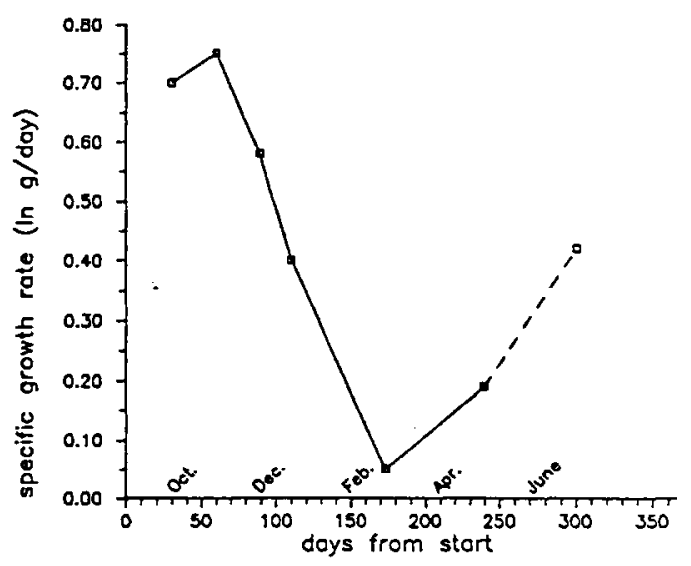

Fig. 3. The specific growth rate (G) (In (g)/day) for Arctic cod (Boreogadus saida) from August 1986 to June 1987. $G=\ln \left(w_{2} /\right.$ $\left.w_{1}\right) /\left(t_{2}-t_{1}\right) \times 100$. The squares indicate measurements. The broken line from April to June shows that there is an inaccuracy resulting from the fact that many of the Arctic cod undergo sexual maturation. 


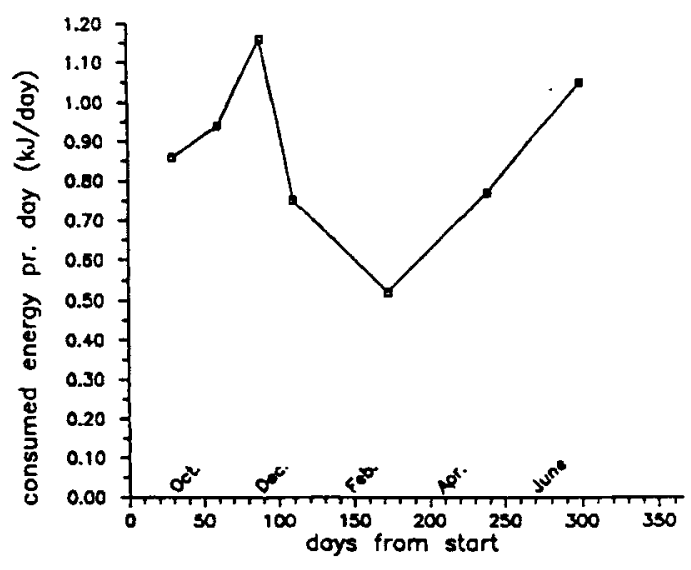

Fig. 4. The consumption (kJ/day) of peeled shrimp per day per fish (Arctic cod) from August 1986 to June 1987. The squares indicate measurements.

Sept.-Dec. the average intake was $0.93 \mathrm{~kJ} /$ day, and in the period Jan.-Feb. the intake was $0.52 \mathrm{~kJ} /$ day.

The ratio between the specific growth rates in Sept./Oct. and Jan./Feb. is 14.5 while the corresponding ratio for the energy consumption is 1.7 .

The food consumption per day per weight $(\mathrm{kJ} /$ day/g) per daily weight increase (g/day) was four times higher in March than in the period Sept.Jan. (see Fig. 5). In the autumn (Sept.-Dec.) the average value of the efficiency is $10.3 \mathrm{~kJ} / \mathrm{g}^{2}$; it

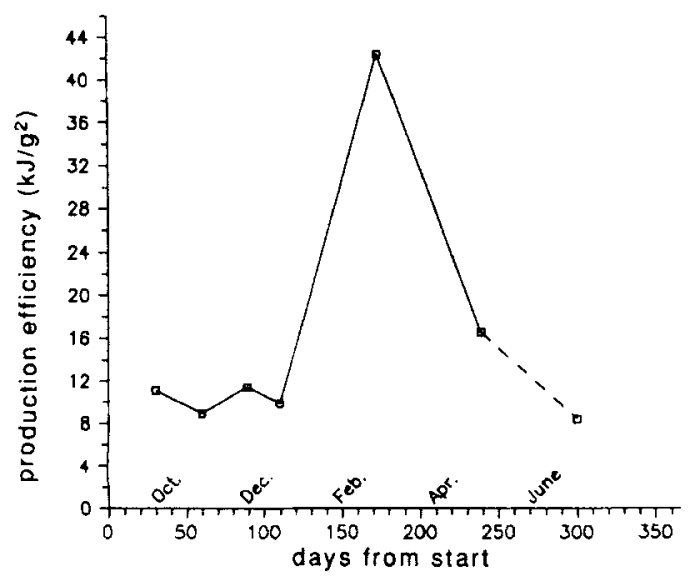

Fig. 5. The production cfficiency (= food consumption (kJ/day) g) per weight increase (g/day)) for Arctic cod (Boreogadus saida) from August 1986 to June 1987. The broken line from April to June shows that there is an inaccuracy resulting from the fact that many of the Arctic cod undergo sexual maturation. The squares indicate measurements

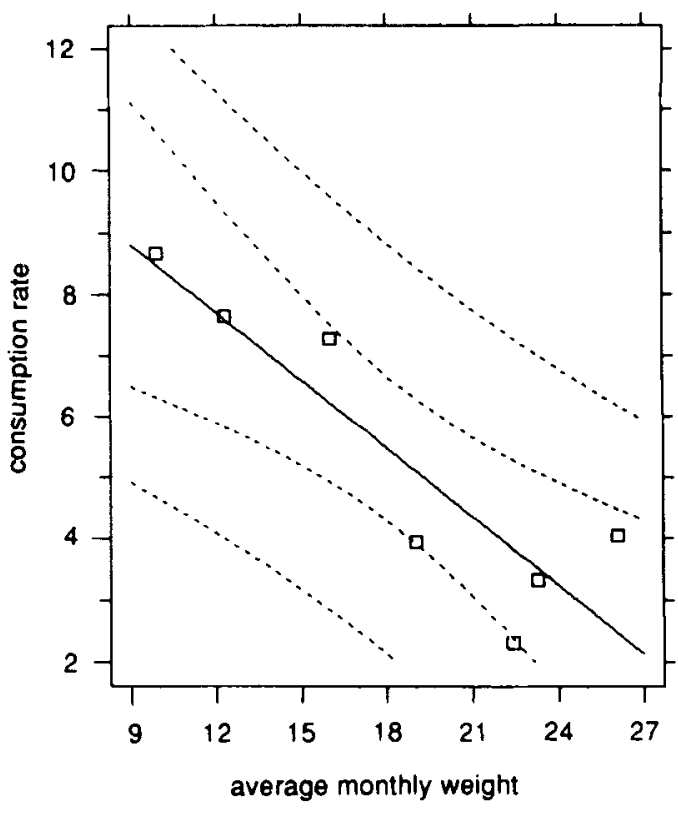

Fig. 6. A regression plot of the relationship between average monthly weight and the consumption rate per day per $100 \mathrm{~g}$ fish weight. The squares represent the measurements. The solid line represents the estimated regression line, while the nearest dotted lines on both sides represent the $95 \%$ confidence limits. The two outer dotted lines represent the predicted limits.

then increases to $42.5 \mathrm{~kJ} / \mathrm{g}^{2}$ in Feb.-March, but falls down to 16.7 and $8.4 \mathrm{~kJ} / \mathrm{g}^{2}$ in May and June.

In order to estimate any possible relationship between average monthly weight and the consumption rate per day per $100 \mathrm{~g}$ fish weight, a simple regression analysis was carried out (Fig. $6)$. The R-squared value was calculated as 0.8 .

In the two last months of the experiments eight of the Arctic cod matured. This was clearly visible from May to June. It was possible to measure the weight and length increases for three of the specimens from April to June. The weight increases were 37,41 , and $66 \%$ and the length increases were $5 \%$ for all three specimens.

\section{Discussion}

In our sample from June 1986 the average length for age groups I and II were $82 \mathrm{~mm}$ and $113 \mathrm{~mm}$. This corresponds to an average specific growth rate of $G=\ln \left(113^{3} / 82^{3}\right) / 360 \times 100=0.27$ for age group I. In our experiment we measured an average growth rate of 0.57 in the autumn and the 
spring, and 0.12 in the winter. It is observed that the experimental values are fairly comparable to the observed value calculated from the size difference between the year classes 1984 and 1985 .

Falk-Petersen et al. (1986) found the average sizes $98 \mathrm{~mm}$ (age group I) and $129 \mathrm{~mm}$ (age group II) in a pooled sample (bottom and pelagic trawls in June-August 1979-1985) of Arctic cod from Spitzbergen coastal waters. Thus it appears that the growth is slightly better in coastal waters than in the ice edges. However, the specific growth rate for age group $I$ in the Spitzbergen coastal waters, $\quad G=\ln \left(129^{3} / 98^{3}\right) / 360 \times 100=0.23$, is $15 \%$ lower than the growth rate we observed in the drift ice (i.e. 0.27). Consequently the main difference between the growth of the coastal and oceanic Arctic cod occur among the young of the year.

In our experiment the growth ceased during the winter. Since fish in Arctic waters experience darkness during the winter months, it is tempting to hypothesise that light is a growth regulating factor. However, since our Arctic cods were exposed to constant illumination, there must be some other factor than light, possibly an internal regulatory mechanism, which strongly influences the growth patterns.

The average consumed energy per day per fish was $0.85 \mathrm{~kJ} /$ day for the whole experimental period. This is a much lower consumption rate than observed in the closely related species cod (Gadus morhua). According to Jobling (1988, page 67), a cod of $28 \mathrm{~g}$ will at $8^{\circ} \mathrm{C}$ have a consumption of $5.35 \mathrm{~kJ} /$ day. We regard this difference as due to the better nutrition conditions in the cod's habitat, i.e. cod is probably better adapted to higher food abundances by having a larger consumption rate.

Jobling (1988) remarks that the consumption rate per unit body weight declines with increasing fish size. A linear regression shows that the fish size explains $80 \%$ of the variability in the consumption rate per day per unit fish weight. However, since the winter months contributed most to the departure from the linear regression line, we conclude that there is some kind of seasonal variation in the consumption rate of Arctic cod.

The average consumption efficiency (consumption of shrimp measured in energetic value divided by weight increase of fish) was $9.9 \mathrm{~kJ} / \mathrm{g}$ in the autumn and the spring, and $29.5 \mathrm{~kJ} / \mathrm{g}$ during the winter. These levels are comparable to these reported by Jobling (1988, table 4.6) for cod
(Gadus morhua) which at $8^{\circ} \mathrm{C}$ has the efficiencies 18.3 and $21.6 \mathrm{~kJ} / \mathrm{g}$ for the size groups 250 and $500 \mathrm{~g}$.

The fact that many of the Arctic cod matured during May and June renders the growth calculations (production efficiency and specific growth rate) for June somewhat inaccurate. The amount of energy required for the production of gonads is not calculated in these preliminary studies. These inaccuracies are shown as broken lines in the specific growth and production efficiency plots in Figs. 3 and 5.

Acknowledgements. - This work is part of the Norwegian Research Program for Marine Arctic Ecology (Pro Mare) and was financed by the Norwegian Research Council for Science and the Humanities/Ministry of the Environment (NAVF/MD, Project no. D5042.057). We thank O. J. Lonne, B. Gulliksen and B. Seim, University of Troms $₫$, for help in collecting Arctic cod in the field. We also thank the referees for improving the manuscript.

\section{References}

Altukhov, K. A. 1979: The reproduction and development of the Arctic Cod, Boreogadus saida, in the White Sea. $J$ Ichthyology 19, 93-101.

Andriashev, A. P. 1964: Fish of the Northern Seas of the USSR. Israel Program for Scientific Translations, Jerusalem. $567 \mathrm{pp.}$

Bain, H. \& Sekerak, A. D. 1978: Aspect of the biology of Arctic cod Boreogadus saida in the central Canadian Arctic. Report by LGL Ltd., Toronto. For Polar Gas Project, Toronto. 104 pp.

Bradstreet, M. S. W. 1982: Occurrence, habitat use, and behavior of seabirds, marine mammals and Arctic Cod at the Pond Inlet ice edge. Arctic. 35, 28-40.

Bradstreet. M. S. W. \& Cross, W. E. 1982: Trophic relationships at high Arctic ice edges. Arctic 35(1), 1-12

Bradstreet, M. S. W., Finley, K. J., Sekerak, A. D., Griffiths, W. B., Evans, C. R., Fabijan, M. F. \& Stallard, H. E. 1986: Aspects of the biology of Arctic cod (Boreogadus saida) and its importance in Arctic marine food chains. Can. Tech. Rep. Fish. Aquat. Sci. No. 1491, 193 pp.

Craig, P. C., Griffiths, W. B., Haldorsen \& McElderry, H. 1982: Ecological studies of Arctic cod (Boreogadus saida) in Beaufort Sea coastal waters, Alaska. Can. J. Fish. Aquat. Sci. 39, 395-406.

Falk-Petersen, I. B., Frivoll, V., Gulliksen, B. \& Haug, T. 1986: Occurrence and age/size relations of Arctic cod, Boreogadus saids (LEPECHIN), in Spitsbergen coastal waters. Sarsia 71, 235-245.

Hognestad, P. T. 1968: Observations on Polar cod in the Barents sea. Rapp. P.-V. Réun. Cons. Int. Explor. Mer 158, 126-130.

Jobling, M. 1983: Growth studies with fish-overcoming the problems of size variation. J. Fish Biol. 22, 153-157.

Jobling, M. 1988: Vekst hos torsk, Undervisningshefie, Universitetet i Troms $\emptyset$. Pp. 65-77.

Klumov. S. K. 1937: Polar cod and their importance for certain 
life processes in the Arctic. Izvestiya Akademiya Nauk SSSR Ser. Biol. No. 14 pp. (Alaska Dept. of fish and games translation).

Lowry. L. F. \& Frost. K. J. 1981: Distribution, growth and foods of Arctic Cod (Boreogadus saida) in the Bering. Chukchi and Beaufort Seas. Can. Field-Nat. 95. 186-191

Lonne, O. J. \& Gulliksen, B. 1989: Size, age and diet of polar cod. Boreogadus saida (Lepechin 1773), in ice-covered waters. Polar Biol. 9. 187-191.

Rass. T. S. 1968: Spawning and development of polar cod. Rapp. et proles-verbaux reunions. Conseil perman, internat. explorat. mer No. 158.

Sekerek. A. D. 1982: Young-of-the-Year Cod (Boreogadus) in Lancaster Sound and Western Baffin Bay. Arctic 35, 75-87. 